\title{
Corrigendum: Cyclin-dependent kinase inhibitors enhance the resolution of inflammation by promoting inflammatory cell apoptosis
}

Adriano G Rossi, Deborah A Sawatzky, Annemieke Walker, Carol Ward, Tara A Sheldrake, Nicola A Riley, Alison Caldicott, Magdalena

Martinez-Losa, Trevor R Walker, Rodger Duffin, Mohini Gray, Elvira Crescenzi, Morag C Martin, Hugh J Brady, John S Savill, Ian Dransfield \& Christopher Haslett

Nature Medicine 12, 1056-1064 (2006); published online 3 September 2006; corrected after print 10 November 2006

In the version of this article initially published, the dose stated for zVAD-fmk administration was incorrect. The methods reported on page 1062 should read, "Twenty-four hours after intrapleural injection of carrageenan, mice were injected i.p. with $10 \mathrm{mg}$ per kg of R-roscovitine and/or 巳 $5 \mathrm{mg}$ per kg of zVAD-fmk (z-Val-Ala-DL-Asp-fluoromethylketone; Bachem).” Similarly, the legend to Figure 4, line 3, should read "C57/bl6 mice 을 were treated with $10 \mathrm{mg}$ per $\mathrm{kg}$ of R-roscovitine (i.p.) and/or $5 \mathrm{mg}$ per kg of zVAD-fmk (i.p. at 4-h intervals)." The authors also made an error reporting the time of administration of K/Bxn serum in the legend to Figure 5, line 14. This should read "Mice ( $n=10$ in each group) were injected twice (days 0 and 2) with K/BxN serum derived from arthritic (day 60) K/BxN transgenic mice." The error has been corrected in the HTML and PDF versions of the article. 